\title{
Immunoreactive adrenomedullin (AM) concentration in maternal plasma during human pregnancy and $\mathrm{AM}$ expression in placenta
}

\author{
Kosuke Kobayashi, Toshiro Kubota, Takeshi Aso, Yukio Hirata ${ }^{1}$, Taihei Imai ${ }^{1}$ and Fumiaki Marumo ${ }^{1}$ \\ Department of Obstetrics and Gynecology and ${ }^{1}$ Second Department of Internal Medicine, Faculty of Medicine, Tokyo Medical and Dental University, \\ 1-5-45 Yushima, Bunkyo-ku, Tokyo 113-0034, Japan \\ (Correspondence should be addressed to T Kubota; Email: t.kubota.gyne@med.tmd.ac.jp)
}

\begin{abstract}
Adrenomedullin (AM) is a novel vasorelaxant peptide, isolated from human pheochromocytoma. Although AM may be involved in the regulation of the cardiovascular system, a number of other mechanisms are also involved. The present study was undertaken to confirm the presence of AM in human maternal circulation and in placental function during pregnancy. Immunoreactive (ir) AM concentrations in maternal plasma were $3.4 \pm 0.7 \mathrm{fmol} / \mathrm{ml}$ (mean \pm s.E.M.) in the first trimester, $3.3 \pm 1.1 \mathrm{fmol} / \mathrm{ml}$ in the second trimester, $7.3 \pm 2.8 \mathrm{fmol} / \mathrm{ml}$ in the third trimester, $4.1 \pm 1.9 \mathrm{fmol} /$ $\mathrm{ml}$ in early puerperium and $3.0 \pm 0.4 \mathrm{fmol} / \mathrm{ml}$ in non-pregnant periods; the concentration in the third trimester was significantly greater than those in other periods. Plasma concentrations of estradiol $\left(\mathrm{E}_{2}\right)$, progesterone, human placental lactogen (hPL) and human chorionic gonadotropin (hCG) were also measured, using RIA kits. Significant correlations have been demonstrated between the concentrations of irAM and those of $\mathrm{E}_{2}$, progesterone and hPL. We therefore examined the expression of AM within the placental tissues using immunohistochemistry and northern blot analysis in order to demonstrate a correlation between the presence of AM in the placenta and maternal plasma. Using immunohistochemistry, we detected AM in the amnion at term and the expression of AM mRNA in human placental tissues using cloned human (h) AM complementary DNA as a probe. This study demonstrates the immunoreactivity of human hAM in maternal plasma during pregnancy, and suggests that hAM in maternal plasma is generated partly from placental tissue.
\end{abstract}

European Journal of Endocrinology 142 683-687

\section{Introduction}

Adrenomedullin (AM) is a novel vasorelaxing hypotensive peptide isolated from human pheochromocytoma (1). Human AM (hAM) consists of 52 amino acid residues with a ring structure stabilized by a disulfide bridge and C-terminal amide. It has partial structural homology with calcitonin gene-related peptide (CGRP) and amylin. It is reported that AM has a marked and long-lasting hypotensive effect in rats in vivo (2). Therefore, it appears likely that AM regulates blood flow.

It has been shown that immunoreactive (ir) AM is present in various human tissues, including adrenal glands, kidney and heart; the adrenal medulla and pheochromocytoma contain extremely high concentrations (3). irhAM has been shown to circulate in human plasma $(4,5)$, suggesting its role as a vasodilatory hormone, and circulating irhAM is known to be secreted mainly from vascular cells (2). Some papers have reported that the concentration of AM is increased in pregnancy $(6,7)$, similarly to other vasodilatory substances such as prostacyclin and prostaglandin $\mathrm{E}_{2}$ $(8,9)$. Montuenga et al. (10) reported that placental tissues of mouse and rat express high levels of AM and AM receptor. Furthermore, irAM and/or AM mRNA has been detected in human feto-placental tissues in the second trimester (11) and at term (12). These findings suggest that the circulation of AM during pregnancy may be related, not only to systemic hemodynamic changes, but also to feto-placental function, in addition to vascular function.

The present study was undertaken to measure the concentrations of hAM and placenta-related hormones in the maternal plasma during pregnancy, and to investigate whether normal placental tissues express the AM gene and/or exhibit AM immunostaining, suggesting the possible involvement of AM in fetoplacental functions during pregnancy. 


\section{Materials and methods}

\section{Materials}

For measurement of hAM, blood samples were obtained from 27 pregnant women (nine in the first trimester (6-12 weeks of gestation), nine in the second trimester (13-28 weeks of gestation), nine in the third trimester (29-40 weeks of gestation)), from nine women in early puerperium, and from six women in the luteal phase of no pregnancy. For immunohistochemical and northern blot analyses, placenta, villi and decidua were obtained immediately after normal vaginal delivery at term and after artificial abortions by dilatation and curettage in the first trimester. These samples were immediately frozen in liquid nitrogen and stored at $-80^{\circ} \mathrm{C}$. The renal function and blood pressure of all the women were normal, and no complications were noted in the pregnant subjects. Informed consent for this study was obtained from patients in the appropriate manner, and the study was approved by the local ethics committee.

\section{Radioimmunoassay of hAM}

RIA of hAM in plasma was performed essentially as previously reported (5), using $\left[{ }^{125} \mathrm{I}\right] \mathrm{hAM}$ as a tracer and synthetic hAM as a standard. hAM and anti-hAM antibody were purchased from Peptide Institute Inc. (Osaka, Japan). The minimum detectable dose in the RIA was $0.5 \mathrm{fmol} /$ tube (95\% confidence) and the $50 \%$ binding intercept was $4.5 \mathrm{fmol} /$ tube. The intra- and interassay coefficients of variation $(n=5)$ were $4.8 \%$ and $8.3 \%$ respectively. The cross-reactivities of the antibody were $100 \%$ with intact $\operatorname{hAM}(1-52), 10 \%$ with $\mathrm{hAM}(13-52)$ and $\mathrm{hAM}(1-10)$, and less than $0.1 \%$ with $\mathrm{hAM}(33-52)$, calcitonin gene-related peptide (CGRP) and amylin. No cross-reactivities were observed with various other vasoactive polypeptides. EDTA plasma samples from the women were separated by centrifugation immediately after collection and stored at $-40{ }^{\circ} \mathrm{C}$. These plasma samples, acidified with equal volume of $0.1 \%$ trifluoroacetic acid (TFA), were loaded onto a Sep-pak C18 column cartridge (Waters Inc., Mildford, MA, USA). The absorbed materials were washed twice, first with $0.1 \%$ TFA and then with $10 \%$ acetonitrile- $0.1 \%$ TFA. The rate of recovery of synthetic hAM was $80 \%$ after passage through the column cartridge (5).

After incubation with anti-hAM monoclonal antibody (final dilution, 1:32 000) at $4^{\circ} \mathrm{C}$ for $24 \mathrm{~h}$, extracted samples or standard synthetic hAM were incubated with $\left[{ }^{125} \mathrm{I}\right] \mathrm{hAM}$ at $4{ }^{\circ} \mathrm{C}$ for a further $24 \mathrm{~h}$. Separation of the bound from the free ligands was performed by the double-antibody method. After aspiration of the supernatant, the radioactivity of the pellets was counted. A typical standard curve for RIA of hAM was obtained.

\section{Measurement of placenta-related steroid or peptide hormones}

The concentrations of estradiol $\left(\mathrm{E}_{2}\right)$, progesterone, human placental lactogen (hPL) and human chorionic gonadotropin (hCG) in the plasma of the women were measured using specific RIA kits ( $\mathrm{E}_{2}$ and progesterone: Diagnostic Product Co., Los Angeles, CA, USA; hPL and hCG: Eikenkagaku Co., Tokyo, Japan). The intra- and interassay coefficients of variation of the results obtained using these four kits did not exceed $10 \%$.

\section{Immunohistochemistry}

Immunohistochemical investigation was performed using the avidin-biotinylated horseradish peroxidase complex (ABC) method. Frozen tissue sections $5 \mu \mathrm{m}$ thick were allowed to dry in air for $30 \mathrm{~min}$, then fixed in $4 \%$ paraformaldehyde for $1 \mathrm{~h}$ after washing in $10 \mathrm{mmol} / \mathrm{l}$ phosphate buffered saline. All sections were then treated with methanol containing $0.3 \%$ hydrogen peroxide for $30 \mathrm{~min}$. After treatment with normal goat serum for $20 \mathrm{~min}$, these sections were incubated with a 1:500 dilution of the anti-hAM monoclonal antibody (Peptide Institute Inc., Osaka, Japan) and with control normal rabbit serum for $2 \mathrm{~h}$ in a humidified chamber at room temperature. The sections were then treated with avidin-biotin-peroxidase complex for $20 \mathrm{~min}$, and stained with $0.1 \%$ diaminobenzidine tetrahydrochloride in $0.02 \%$ hydrogen peroxide. Counterstaining was performed with hematoxylin.

\section{RNA preparation and northern blot analysis}

Total RNA was extracted by the acid guanidium thiocyanate-phenol-chloroform method. Frozen tissue specimens were homogenized using a Polytron homogenizer in guanidinium solution containing $4 \mathrm{~mol} / \mathrm{l}$ guanidinium thiocyanate, $25 \mathrm{mmol} / \mathrm{l}$ sodium citrate, $0.5 \%$ sarcosyl and 1\% 2-mercaptoethanol. Northern blot analysis was performed essentially in the same manner as described previously (13). Total RNA (20 $\mu \mathrm{g})$ was fractionated by formaldehyde/1.1\% agarose gel electrophoresis and tranferred to a MagnaGraph nylon membrane (Micron Separations, Westborough, MA, USA). The cDNA probe for hAM was labeled with $\left[{ }^{32} \mathrm{P}\right] \mathrm{dCTP}$ (Amersham Ltd, Amersham, Bucks, UK) by random primed labeling methods. After u.v. wave cross-linking, the membrane was incubated with the labeled probes at $42{ }^{\circ} \mathrm{C}$ for $16 \mathrm{~h}$ in a hybridization buffer containing $1 \mathrm{~mol} / \mathrm{l} \mathrm{NaCl}, 50 \%$ formamide, $1 \%$ sodium dodecyl sulfate (SDS) and $250 \mu \mathrm{g} / \mathrm{ml}$ salmon sperm DNA. The membrane was washed with a solution containing $0.1 \times \mathrm{SSPE} \quad(15 \mathrm{mmol} / \mathrm{l} \mathrm{NaCl}, 1 \mathrm{mmol} / \mathrm{l}$ $\mathrm{NaH}_{2} \mathrm{PO}_{4}, 0.1 \mathrm{mmol} / \mathrm{l}$ EDTA) $-0.5 \%$ SDS at $37^{\circ} \mathrm{C}$, and autoradiographed on Kodak ZAR-1 film with an intensifying screen at $-80^{\circ} \mathrm{C}$ for $24 \mathrm{~h}$. 


\section{Statistics}

Data are expressed as the mean \pm s.E.M. Statistical analysis was performed by analysis of variance (ANOVA) to determine the significance of differences, with a level of $P<0.05$ being accepted as statistically significant. Correlation was estimated using linear regression analysis.

\section{Results}

\section{Concentrations of $A M$ and correlations between $A M$ and other hormones in maternal plasma}

The mean concentrations of irAM in maternal plasma were $3.0 \pm 0.4 \mathrm{fmol} / \mathrm{ml}$ in non-pregnant periods, $3.4 \pm 0.7 \mathrm{fmol} / \mathrm{ml}$ in the first trimester, $3.3 \pm 1.1 \mathrm{fmol} /$ $\mathrm{ml}$ in the second trimester, $7.3 \pm 2.8 \mathrm{fmol} / \mathrm{ml}$ in the third trimester and $4.1 \pm 1.9 \mathrm{fmol} / \mathrm{ml}$ in early puerperium (Fig. 1); the concentration in the third trimester was significantly greater than those in other periods. As plasma irAM increased, corresponding increases in plasma $\mathrm{E}_{2}$, progesterone and hPL concentrations were observed. Significant positive correlations were found between the concentration of irAM and those of $\mathrm{E}_{2}$ $(r=0.53, P<0.05)$, progesterone $(r=0.57, P<0.001)$ and hPL $(r=0.50, P<0.05)$; however, there was no significant correlation between irAM and hCG concentrations (Table 1 ).

\section{Immunohistochemistry}

The epithelial cells of term amnion stained with antihAM monoclonal antibody, demonstrating immuno-

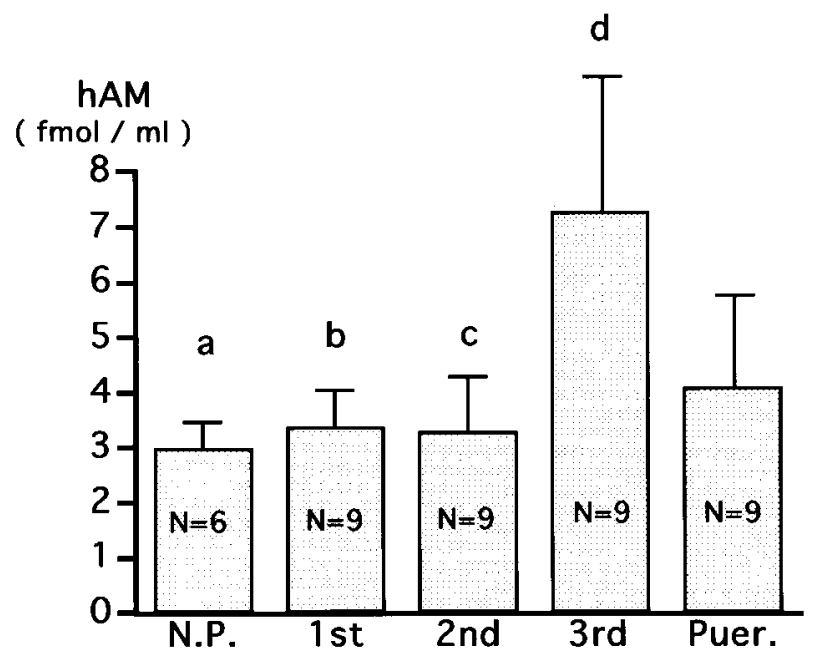

Figure 1 Concentrations of irhAM in maternal plasma of non-pregnant women (N.P.) and those in the first trimester (1st), second trimester (2nd), third trimester (3rd) and puerperium (Puer.) (mean \pm S.E.). Concentrations in the third trimester were significantly greater than those in other periods: $P<0.05$ for $\mathrm{d}$ compared with $\mathrm{a}, \mathrm{b}$ and $\mathrm{c}$.
Table 1 Correlations (by linear regression analysis) between irhAM and placental hormone concentrations in maternal plasma during pregnancy.

\begin{tabular}{lccl}
\hline Hormone & $\begin{array}{c}\text { No. of } \\
\text { samples }\end{array}$ & $\begin{array}{c}\text { Correlation } \\
\text { coefficient } \\
\text { vs irhAM }\end{array}$ & $\begin{array}{c}\text { Statistical } \\
\text { significance }\end{array}$ \\
\hline Estradiol & 24 & 0.53 & $P<0.05$ \\
Progesterone & 24 & 0.57 & $P<0.001$ \\
hPL & 20 & 0.50 & $P<0.05$ \\
hCG & 20 & 0.19 & NS
\end{tabular}

NS, not significant.

histochemically that hAM was present in amnion epithelial cells (Fig. 2). However, no immunoreactivity was seen in placental villi of early pregnancy and term, or in decidua in early pregnancy.

\section{Northern blot analysis}

As shown in Fig. 3, northern blot analysis of total RNA extracted from placental tissues in the first trimester and at term revealed the presence of a distinct hybridizing band corresponding to the size of AM mRNA $(1.6 \mathrm{kbp})$ in each tissue. The concentrations of AM mRNA in term placenta (villi + amnion tissue) were greater than that in villi or decidua of early pregnancy.

\section{Discussion}

This study has demonstrated changes in the concentration of irhAM in maternal plasma during human pregnancy and the expression of hAM mRNA in human placenta. The use of a specific and sensitive RIA for hAM enabled us to measure the plasma concentration of irhAM in human plasma and urine $(4,5)$. We were clearly measuring irhAM concentration in maternal plasma in this RIA, because the crossreactivities of the antiserum to hAM(33-52), CGRP and amylin were much weaker than those to AM, and the plasma extract gave a parallel displacement of the label in parallel with the standard AM.

The concentration of irhAM in maternal plasma was increased in the third trimester of pregnancy, and the results appear to be comparable to those recently reported by others $(6,7)$. However, a recent report revealed no significant difference in mean maternal plasma concentrations of AM from week 8 to week 40 of pregnancy (14). The probable reasons for this discrepancy are the different hAM antibodies used in the RIAs, and the wide standard deviation of hAM concentrations as a result of the small sample size of our study. Our data provide evidence that the placenta produces AM and secretes it into the maternal circulation, particularly during the third trimester of pregnancy. The finding of increased concentrations in late pregnancy, followed by a significant decrease in the 

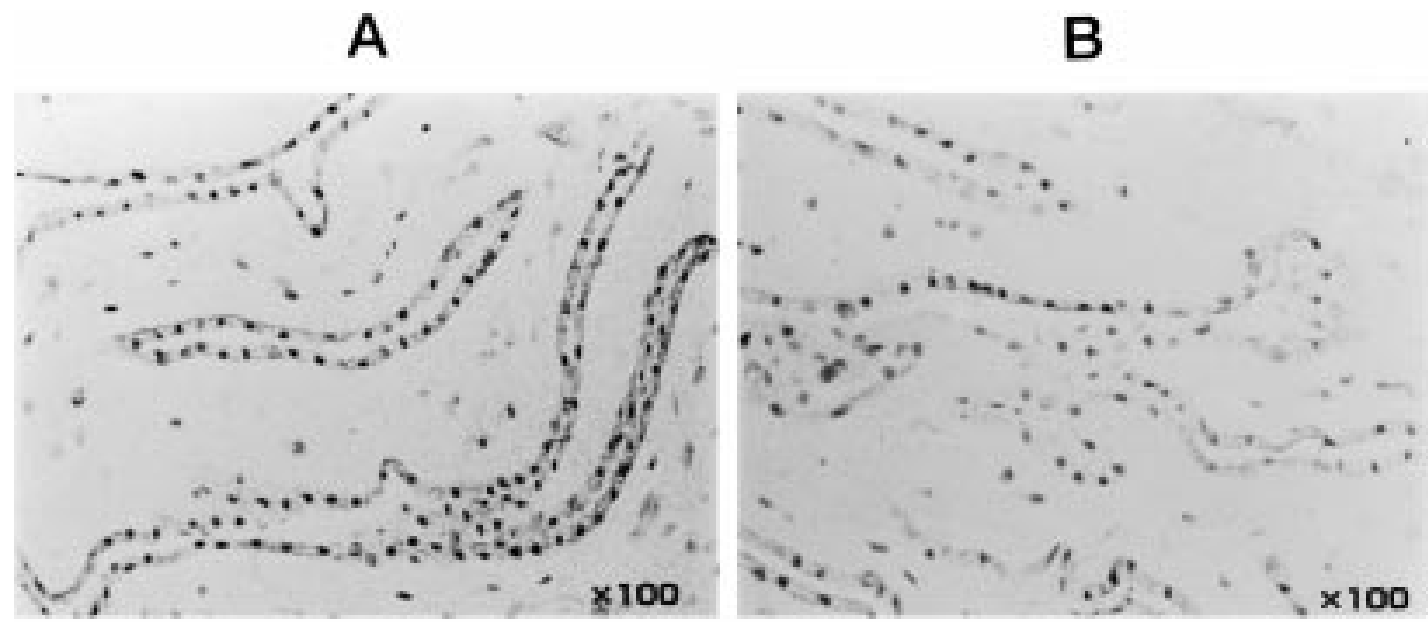

Figure 2 Immunohistochemistry of term amnion. (A) Stained with anti-hAM monoclonal antibody. (B) Control, without anti-AM antibody. The amnion epithelial cells are positively stained, demonstrating the immunohistochemical localization of hAM. Original magnification: $\times 100$.

puerperium, and the demonstration of AM mRNA in placenta and decidua, suggest that the placenta is a source of AM during pregnancy. We also demonstrated a significant correlation between the concentrations of irhAM and those of sex steroids or hPL, suggesting that the release of irhAM during pregnancy is a reflection of the size of the placenta. Furthermore, irhAM was detected in term amnion epithelial cells by use of an immunohistochemical procedure - a finding that is confirmed by other reports showing increased concentrations of hAM in amniotic fluid (6) and AM mRNA in feto-placental tissues of term pregnancy (11). These results suggest that AM may have an osmoregulatory role in the fetal and amniotic compartments. In this study, we demonstrated that AM mRNA was abundant in term placenta, but that smaller amounts of mRNA specific for AM were present in villi of early pregnancy. Immunostaining was positive only in term amniotic epithelium, but not in placental villi or decidua of early and term pregnancy. However, Marinoni et al. (12) have reported the presence of irhAM in extravillous trophoblasts of term placenta by immunohistochemical studies. This discrepancy in findings may be due to the low sensitivity of the immunohistochemical method in our study, and to the different procedures used for sampling the term placentae.

Our study has demonstrated that maternal plasma irhAM concentrations in the third trimester were significantly increased, compared with those in other gestational, puerperal and non-pregnant periods. However, the physiological significance of this increase in the irhAM concentrations during the third trimester remains unclear. The decreased vascular tone and the modifications to renal hemodynamics occurring during pregnancy may be attributed in part to changes in the synthesis of endothelial-derived vasoactive substances (15). It has been shown that plasma concentrations of a variety of vasoactive peptides, such as endothelin (16), prostaglandin $E_{2}(17)$ and prostacyclin (8), are increased in the third trimester, partly for the same reasons. In addition, our results suggest that the increase in plasma irhAM concentrations in the third trimester is the consequence of enhanced production of AM by the placenta.

AM has a vasodilatory effect on a variety of blood vessels in many species and may be important in controlling vascular tone in addition to local blood flow (5). The peptide also exerts a number of pharmacological effects in a variety of tissues (18), and many of its actions seem to be related to the homeostatic control of fluid, particularly electrolyte homeostasis, and the cardiovascular status in general (19). However, the physiological functions of AM in the maternal plasma during pregnancy remain unknown. Normal pregnancy is associated with a characteristic change in systemic and renal hemodynamics. The vascular endothelium generates both vasodilators and vaso-

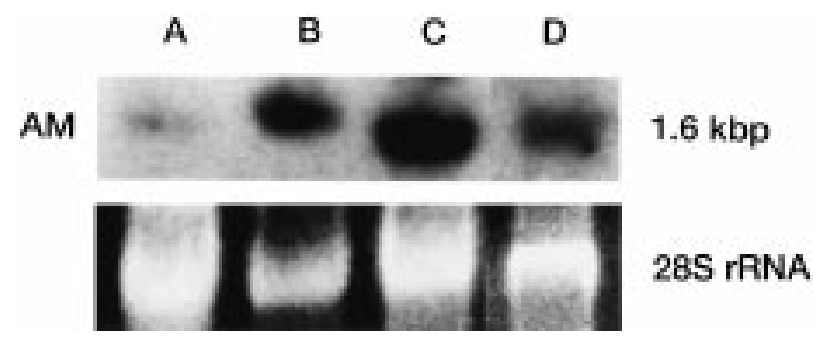

Figure 3 Expression of hAM mRNA in human placenta by northern blot analysis, revealing a distinct hybridization band corresponding to the size of hAM mRNA (1.6 kbp) in each tissue. The lower panel shows ethidium bromide stained $28 \mathrm{~S}$ rRNA bands as a loading control. A: Villi in early pregnancy; B: decidua in early pregnancy; $\mathrm{C}$ : villi in term pregnancy; $\mathrm{D}$ : whole placental tissue in term pregnancy. 
constrictors, and a correct balance between these substances may be crucial to the adaptive changes occurring during pregnancy (9). Therefore, AM is believed to be responsible for the marked resistance to the pressor effects of angiotensin II (20) and endothelin, resulting in a modest decrease in blood pressure during the course of a normal pregnancy (21).

In conclusion, the present study has demonstrated that maternal plasma irhAM concentrations in the third trimester were significantly greater than those in other gestational periods. IrhAM was detected in term amnion epithelial cells by the use of an immunohistochemical procedure, and term placental tissue was found mainly to express AM mRNA. These results suggest that plasma irhAM may be generated partly from placental tissue, and may have a physiological role in the control of cardiovascular status and feto-placental function during human pregnancy. However, further studies are required to clarify the role of AM in the pathophysiologic characteristics of normal pregnancy.

\section{Acknowledgements}

The work was supported by a science research grant (08671873) from the Ministry of Education, Science and Culture of Japan to $\mathrm{T}$ Kubota. We gratefully acknowledge the excellent technical skills of Miss Kyoko Sato in SRL Incorporation, Hachioji, Japan for measuring irhAM in plasma samples.

\section{References}

1 Kitamura K, Kangawa K, Kawamoto M, Ichiki Y, Nakamura S, Matsuo H \& Eto T. Adrenomedullin: a novel hypotensive peptide isolated from human pheochromocytoma. Biochemical and Biophysical Research Communications 1993192 553-560.

2 Sugo S, Minamino N, Shoji H, Kangawa K, Kitamura K, Eto T \& Matsuo H. Interleukin-1, tumor necrosis factor, and lipopolysaccharide additively stimulate production of adrenomedullin in vascular smooth muscle cells. Biochemical and Biophysical Research Communications 1995207 25-32.

3 Washimine H, Kitamura K, Ichiki Y, Yamamoto Y, Kangawa K, Matsuo $\mathrm{H}$ \& Eto $\mathrm{T}$. Immunoreactive proadrenomedullin N-terminal 20 peptide in human tissue, plasma and urine. Biochemical and Biophysical Research Communications 1994202 1081-1087.

4 Kitamura K, Ichiki Y, Tanaka M, Kawamoto M, Matsuo H \& Eto T. Immunoreactive adrenomedullin in human plasma. FEBS Letter $1994341288-290$.

5 Sato K, Hirata Y, Imai T, Iwashita M \& Marumo F. Characterization of immunoreactive adrenomedullin in human plasma and urine. Life Science 199557 189-194.

6 Di Iorio R, Marinoni E, Scavo D, Letizia C \& Cosmi EV. Adrenomedullin in pregnancy. Lancet 1997349328.
7 Di Iorio R, Marinoni E, Letizia C, Alo P, Villaccio B \& Cosmi EV. Adrenomedullin, a new vasoactive peptide, is increased in preeclampsia. Hypertension 199832 758-763.

8 Goodmann RP, Kiiam AP, Brash AR \& Branch RA. Prostacyclin production during pregnancy: comparison of production during pregnancy complicated by hypertension. American Journal of Obstetrics and Gynecology 1982142 817-822.

9 Benigni A, Gregorini G \& Frusca T. Effect of low dose aspirin on fetal and maternal generation of thromboxane by platelets in women at risk for pregnancy-induced hypertension. New England Journal of Medicine 1989321 357-362.

10 Montuenga LM, Martinez A, Miller MJ, Unsworth EJ \& Cuttitta F. Expression of adrenomedullin and its receptor during embryogenesis suggests autocrine or paracrine models of action. Endocrinology 1997138 440-451.

11 Macri CJ, Martinez A, Moody TW, Gray KD, Miller MJ, Gallagher M \& Cuttitta F. Detection of adrenomedullin, a hypotensive peptide, in amniotic fluid and fetal membranes. American Journal of Obstetrics and Gynecology 1996175 906-911.

12 Marinoni E, Di Iorio R, Letizia C, Villaccio B, Scucchi L \& Cosmi EV. Immunoreactive adrenomedullin in human fetoplacental tissues. American Journal of Obstetrics and Gynecology $1998179784-787$.

13 Imai T, Hirata Y, Iwashita M \& Marumo F. Hormonal regulation of rat adrenomedullin gene in vasculature. Endocrinology 1995 136 1544-1548.

14 Di Iorio R, Marinoni E, Letizia C, Villaccio B, Alberini A \& Cosma EV. Adrenomedullin production is increased in normal human pregnancy. European Journal of Endocrinology 1999140 201-206.

15 Benigni A, Gaspari F, Orisio S, Bellizzi L, Amuso G, Frusca T \& Remuzzi G. Human placenta expresses endothelin gene and corresponding protein is excreted in urine in increasing amounts during normal pregnancy. American Journal of Obstetrics and Gynecology $1991164844-848$.

16 Usuki S, Saitoh T, Sawamura T, Suzuki N, Shigemitsu S, Yanagisawa M, Goto K, Onda H, Fujino M \& Masaki T. Increased maternal plasma concentration of endothelin-1 during labor pain or on delivery and the existence of a large amount of endothelin-1 in amniotic fluid. Gynecological Endocrinology 1990 4 85-97.

17 Messo CO, Fischer C, Hoffman LH \& Frolich JC. Assessment of uterine and renal prostaglandin synthesis in pregnancy by gas chromatography mass spectrometry. INSERM Symposium $197991167-170$.

18 Kitamura K, Kangawa K, Matsuo H \& Eto T. Adrenomedullin: implications for hypertension research. Drugs 199549 485-495.

19 Samson WK \& Murphy TC. Adrenomedullin inhibits salt appetite. Endocrinology 1997138 613-616.

20 Gant NF, Daley GI, Chand S, Whalley PJ \& MacDonald PC. A study of angiotensin II pressor response throughout primigravid pregnancy. Journal of Clinical Investigation $1973 \mathbf{5 2}$ 2682-2689.

21 Lees MM, Taylor SH, Scott DB \& Kerr MG. A study of cardiac output at rest thoughout pregnancy. Journal of Obstetrics and Gynaecology of the British Commonwealth 196774 319-328.

Received 18 October 1999

Accepted 9 February 2000 